\section{FEEDING BEHAVIOR}

\section{How to hover}

Sci. Adv. 4, eaat2980 (2018)

Hovering is a tricky skill, but one that several species of birds and bats have perfected in order to consume nectar from flowers. The aerodynamics involved in supporting each animal's body weight while it hovers have been hard to pin down but recently, a Stanford team combined a highresolution aerodynamic force platform with a high-speed camera rig to capture and compare the details.

They looked at seventeen species of hummingbird and three bats found in Costa Rica. The hummingbirds generally were more efficient: they deployed quicker, more symmetrical wing beats than the bats. The birds also generated more force during their upstrokes, while bats, with their larger wings, supported their weight on the down stroke with slower beats. Regardless, each used similar amounts of energy relative to their body mass to hover. $E P N$

https://doi.org/10.1038/s41684-018-0188-3

\section{BIOLOGICAL TECHNIQUES}

\section{A flume for fish}

PLoS ONE 13, e0199712 (2018)

Adult zebrafish are fast, capable of covering $15 x$ their body length every second. Larval zebrafish are much slower, but pick up the pace as they age. To measure bursts of activity and sustained swimming speeds, researchers need special flumes and will often customize set-ups to use with zebrafish across life stages.

Writing in PLoS One, a research team from Boston present step-by-step instructions to build a zebrafish-scale flume that can be used across the animal's lifespan. The set-up is built with PVC components, a modified aquarium tank, and small commercially available pumps and flow meters. The water flow is controlled and monitored by inexpensive, opensource Arduino microprocessors, and the FlowControl software the team developed is available on GitHub. The number of pumps and valves operating in the flume can be adjusted to accommodate the age, and maximum swimming speed, of the fish. EPN

https://doi.org/10.1038/s41684-018-0189-2

\section{LINEAGE TRACKING}

\section{CRISPR-barcoding the mouse \\ Science 361, eaat9804 (2018)}

The adult mouse has 10 billion cells. It'd be an immense, if impossible, task to trace the lineage of each cell back to the mouse embryo through individual snap shots in time. But CRISPR is helping researchers take on the challenge.

The CRISPR-Cas9 system can be used to add or delete small sequences of DNA in developing organisms; the animal repairs these, but a "scar" is left behind that is then inherited in future cell divisions. Such barcodes have been used for lineage tracing in zebrafish, from work at the University of Washington in Seattle. Researchers at Harvard Medical School have now applied a CRISPR-barcoding approach to the mouse, following heart, limb, and placental cells in a 12-day old embryo back to their origins.

$E P N$

https://doi.org/10.1038/s41684-018-0190-9

\section{REGENERATION}

\section{Dedifferentiation for regeneration}

Science https://doi.org/10.1126/science.aaq0681 (2018)

The axolotl has the remarkable ability to regenerate lost limbs. New appendages develop from an assemblage of cells called the blastema, which accumulates near the amputation point. What those cells are and how they know to start dividing again has been unclear. But newly developed transgenic axolotls are helping to reveal the salamander's secrets.

The animals were modified to express a fluorescent protein in their connective tissue cells that can be tracked before and after an experimental forelimb amputation. The researchers involved also analyzed the activity of genes in different axolotl cells with single-cell RNA sequencing techniques. Together, the results suggest that connective tissue cells in the uninjured portion of the limb de-differentiate into progenitor cells that then regenerate the missing appendage.

https://doi.org/10.1038/s41684-018-0191-8

Ellen P. Neff

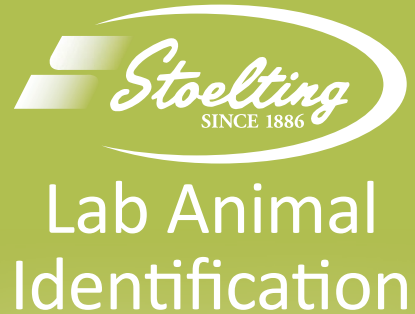

SMALL ANIMAL EARTAGS AND MARKERS
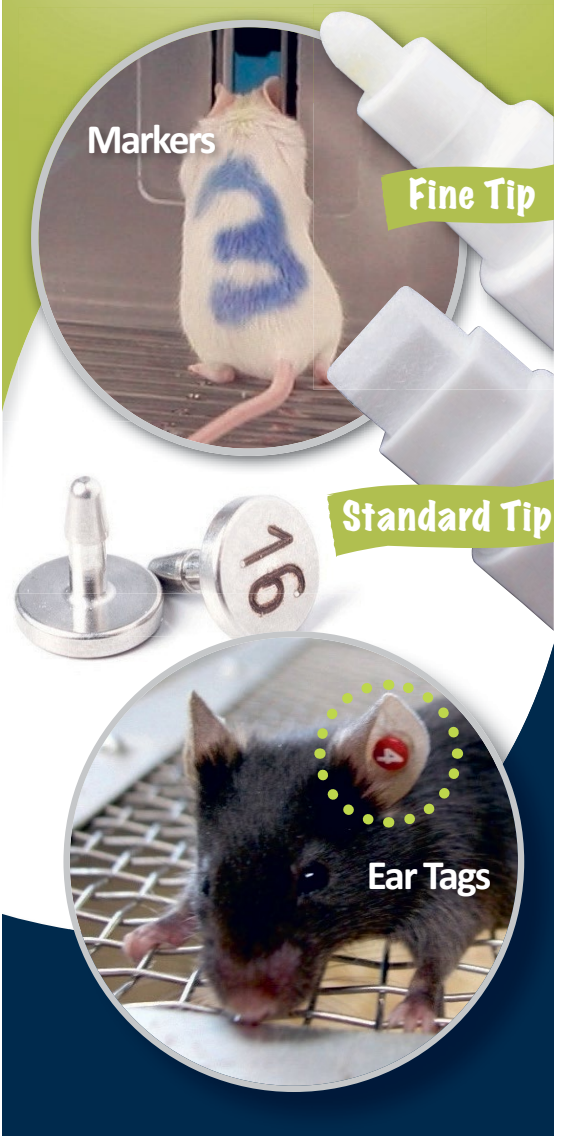

Ear Tag and Marker Features:

- Quick and easy identification

- Long-lasting

- Nontoxic, non-hazardous

- Multiple colors options available

Contact Stoelting for details! Visit

www.StoeltingCo.com

or email us at

info@StoeltingCo.com 